\title{
LA POLLA DE CERVANTES CONSIDERACIONES SOBRE CÓMO LA REMETERÍA Y QUÉ PAJILLAS ECHARÍA
}

\author{
Fernando Iwasaki Cauti
}

Siempre habíamos creído que los campos semánticos de la polla española y de la polla hispanoamericana no sólo eran distintos, sino incongruentes entre sí. No obstante, un análisis riguroso del vocabulario naipesco de los siglos XVI y XVII revela que la polla española y la polla hispanoamericana tuvieron el mismo origen timbero. Así, mientras que en América Latina la polla conservó su acepción de juego y apuesta, en España se convirtió en la excepción al juego y la apuesta. La polla fue una pertinaz obsesión para los españoles del Siglo de Oro. En realidad, también para los españoles del siglo XXI, aunque la polla moderna es la misma pero diferente. Con ocasión del IV centenario de la publicación del Quijote, se ha hablado mucho del corazón de Cervantes, de la cabeza de Cervantes y hasta de la mano de Cervantes. Por eso la presente investigación quiere ser un discreto homenaje a la polla de Cervantes.

Fernando Iwasaki Cauti. Nació en Lima en 1961. Realizó sus estudios de licenciatura y maestría en historia en la Pontificia Universidad Católica del Perú y los de doctorado en la Universidad de Sevilla. Desde 1989 reside en Sevilla. Entre sus obras más recientes se cuentan la novela Neguijón (Ed. Alfaguara, 2005), los cuentos Ajuar funerario (Ed. Páginas de Espuma, 2004) y Un milagro informal (Ed. Alfaguara, 2003), la novela Libro del mal amor (Ed. R.B.A. Libros, S.A., 2001). Actualmente es director de la revista literaria Renacimiento, director de la Fundación Cristina Heeren de Arte Flamenco y columnista del diario $A B C$. Es "Premio Copé" de Narrativa (Lima, 1998); Conference on Latin American History Grant Award (New York, 1996); Premio Fundación del Fútbol Profesional (Madrid, 1994) y Premio de Ensayo "Alberto Ulloa" (Lima, 1987). Ha sido colaborador del Diario de Sevilla (1999-2000), La Razón (1998-2000), El País (19971998), Diario 16 (1991-1996), Expreso (1986-1989) y La Prensa (1983-1984).

Estudios Públicos, 100 (primavera 2005). 
César el juego aprendió
y un día que le jugó,
teniendo basto, malilla,
punto cierto y espadilla,
la tal polla remetió.

(Calderón de la Barca, Nadie fie su secreto.)

\section{$\mathrm{U}$}

na polla en la mayoría de países hispanoamericanos es una inofensiva quiniela hípica o deportiva, mientras que en España es un obsceno vulgarismo que define al órgano genital masculino, tal como lo admite la Academia Española desde la décimo novena edición de su Diccionario en 1985. ¿Por qué en América Latina una polla es una apuesta y en España es algo que nadie se apostaría? Me propongo demostrar que alguna vez ambas pollas fueron la misma, hasta que los españoles perdieron la suya.

\section{Desflorando a Cervantes}

Una de las certezas más compartidas por los biógrafos de Cervantes vendría a ser la afición del autor del Quijote por los juegos de naipes, pues Cervantes no sólo citaba los juegos por sus nombres, sino hasta las trampas o fullerías más conocidas ${ }^{1}$. Aquellos engaños, trapacerías y añagazas de tahúres recibían el nombre de "flores" en el argot de la timba ${ }^{2}$, y Cervan-

1 "A lo largo de su obra [Cervantes] se destapó como un gran catedrático de los juegos de naipes, conocía su jerga y enumera infinidad de modalidades y variantes en sus libros: la veintiuna, la quínola, el parar o la andaboba . . . No son pocos los pasajes, y en no pocas de sus obras, en los que certifica su conocimiento de tahúres, garitos y tretas del juego de los naipes. Seguramente, como la mayoría de los hombres de su tiempo, debió de jugar a cartas, porque no había muchos más entretenimientos en aquella sociedad ni estaba al alcance de la gente de cualquier condición otra holgura que esa de la baraja, en ventas solitarias o en ciudades importantes. Jugaban los ricos y los pobres, los reyes, los nobles y los plebeyos, los rústicos y los villanos. Lo lógico es que alguien como Cervantes, que había pasado buena parte de su vida entre soldados, en cautiverio o en las posadas del camino, supiese jugar a cartas, y jugase". En Andrés Trapiello, Las vidas de Miguel de Cervantes (Madrid: Biblioteca ABC, 2004), p. 127.

${ }^{2}$ En su Tesoro de la lengua castellana o española impreso en 1611, Sebastián de Covarrubias recoge las siguientes acepciones para la voz FLOR: "9. Flor, entre farsantes burladores, llaman aquello que traen por ocasión y escusa, cuando quieren sacarnos alguna cosa como decir que son caballeros pobres, o soldados que vienen perdidos, o que han salido de cautiverio, y desas flores son tantas las que hay en el mundo, que le tienen desflorado . . . 12. Juego de la flor, juego de tahures" (cito la edición de Castalia, Madrid, 1944, pp. 552-553). Por otro lado, en el Diccionario de autoridades impreso en 1732 encontramos la siguiente entrada: "FLOR. Entre los fulleros significa la trampa y engaño que se hace en el juego" (cito la edición facsímil de Gredos, Madrid, 1990, tomo II). 
tes hizo alarde de sus conocimientos fulleros en Rinconete y Cortadillo, cuando a petición de Monipodio el pícaro enumeró sus habilidades con la baraja:

Yo - respondió Rinconete- sé un poquito de floreo de Vilhán: entiéndase el retén; tengo buena vista para el humillo; juego bien de la sola, de las cuatro y de las ocho; no se me va por pies el raspadillo, verrugueta y el colmillo; éntrome por la boca de lobo como por mi casa, y atreveríame a hacer un tercio de chanza mejor que un tercio de Nápoles, y a dar astillazo al más pintado mejor que dos reales prestados ${ }^{3}$.

Redactada entre 1601 y 1602, Rinconete y Cortadillo no fue la única obra donde Cervantes demostró su sabiduría de garito, pues en la comedia Pedro de Urdemalas volvió a florearse con las "flores" de los tahúres:

Luego fui mozo de mulas, $y$ aún de un fullero lo fui, que con la boca del lobo se tragara a San Quintin; gran jugador de las cuatro, y con la sola le vi dar tan mortales heridas, que no se pueden decir. Berrugueta $y$ ballestita, el respaldillo $y$ hollín jugaba por excelencia, y el Maese Juan hi de ruin. Gran sage del espejuelo, $y$ del retén tan sutil, que no se le viera un lince con los antojos del $\mathrm{Cid}^{4}$.

En un espléndido trabajo, Jean-Pierre Etienvre sugiere que la retahíla cervantina de las "flores" le parece más un recurso retórico que una descripción realista. Es decir, "Retórica de la acumulación (enumeratio), procedimiento elemental (en el sentido estricto del adjetivo), juego fácil con los juegos, parecido (sin ser tan extremado) a la acumulación rabelesiana de los juegos de Gargantúa. Juego que Cervantes repite, pero con variantes, como

\footnotetext{
${ }^{3}$ Miguel de Cervantes, Rinconete y Cortadillo, en Obras Completas (Madrid: Editorial Aguilar, 1992), t. II, p. 89. Según el Diccionario de autoridades, "Cortadillo. En la Germanía es cierta flor, que usan los fulléros en el juego de los naipes" (Diccionario de autoridades, t. I).

${ }^{4}$ Miguel de Cervantes, Pedro de Urdemalas, Jornada I, en Obras completas, t. I, p. 621 (Pedro de Urdemalas fue compuesta entre 1610 y 1611).
} 
para convencernos de que la fullería es letra viva y mundo abierto"5. Por lo tanto, aunque Cervantes hubiera sido un jugador más o menos empedernido, sus "flores" habrían sido sembradas para seducir con sus aromas a unos lectores que el autor presumía familiarizados con la cultura del naipe ${ }^{6}$.

Sin embargo, en toda la primera parte de Don Quijote de la Mancha (1605) no encontramos ni una sola mención a las "flores" del juego, porque las fullerías más bien se concentran en las Novelas ejemplares (1613) o en sus comedias y entremeses ${ }^{7}$. No obstante, en la segunda parte del Quijote (1615) sí hallamos dos referencias puntuales al juego y los naipes. La primera es una frase que se pronuncia durante la apócrifa aventura de la cueva de Montesinos: "Y cuando así no sea — respondió el lastimado Durandarte con voz desmayada y baja-, cuando así no sea, ¡oh, primo!, digo paciencia y barajar"8. Esta expresión fue comentada por otro personaje -un primo, humanista trasnochado- en el capítulo siguiente, quien después de amonestar a Sancho por su impertinencia se explayó así:

Yo, señor Don Quijote de la Mancha, doy por bien empleadísima la jornada que con vuesa Merced he hecho, porque en ella he granjeado cuatro cosas. La primera, haber conocido a vuestra merced, que lo tengo a gran felicidad. La segunda, haber sabido lo que se encierra en esta cueva de Montesinos, con las mutaciones de Guadiana y de las lagunas de Ruidera, que me servirán para el Ovidio español que traigo entre manos. La tercera, entender la antigüedad de los naipes, que, por lo menos, ya se usaban en tiempo del emperador Carlo Magno, según puede colegirse de las palabras que vuesa merced dice que dijo Durandarte, cuando al cabo de aquel grande espacio que estuvo hablando con él Montesinos, él despertó diciendo: "Paciencia y barajar". Y esta razón y modo de hablar no la pudo aprender encantado, sino cuando no lo estaba, en Francia y en tiempo del referido emperador Carlo Magno. Y esta

${ }^{5}$ Jean-Pierre Etienvre, "Paciencia y barajar: Cervantes, los naipes y la burla", en Anales de literatura española IV (Alicante: Universidad de Alicante, 1985), p. 139.

6 "Original y explícito a la vez, el juego cervantino se vale de los juegos -y particularmente del más vulgar entre ellos, los naipes - como de un lenguaje común que se vuelve, bajo su pluma, lenguaje de creación. Y ese lenguaje, como cualquier otro lenguaje o, mejor dicho, el lenguaje en general, no sirve a Cervantes para representar la realidad, sino para trastocarla: con naipes del montón baraja tópicos" (Etienvre, "Paciencia y barajar...", p. 142).

${ }^{7}$ Jean-Pierre Etienvre ha levantado un minucioso inventario de las expresiones naipescas en la obra de Cervantes - "Léxico de los naipes en la obra de Cervantes"- y parece evidente que la mayoría de las referencias son posteriores a la primera edición del Quijote (Etienvre, "Paciencia y barajar..., op. cit.", pp. 152-155).

${ }^{8}$ Miguel de Cervantes: Don Quijote de la Mancha, parte II, cap. XXIII, en Obras completas, t. II, p. 668 (las cursivas son nuestras). 
averiguación me viene pintiparada para el otro libro que voy componiendo, que es Suplemento de Virgilio Polidoro, en la invención de las antigüedades; y creo que en el suyo no se acordó de poner la de los naipes, como la pondré yo ahora, que será de mucha importancia, y más alegando autor tan grave y tan verdadero como es el señor Durandarte. La cuarta es haber sabido con certidumbre el nacimiento del río Guadiana, hasta ahora ignorado de las gentes ${ }^{9}$.

La segunda referencia proviene del capítulo XLXIX, cuando Sancho pretende prohibir las casas de juego en la ínsula Barataria y es reconvenido así por un funcionario:

Ésta, a lo menos - dijo un escribano-, no la podrá vuesa merced quitar, porque la tiene un gran personaje, y más es, sin comparación, lo que él pierde al año que lo que saca de los naipes. Contra otros garitos de menor cuantía podrá vuesa merced mostrar su poder, que son los que más daño hacen y más insolencias encubren; que en las casas de los caballeros principales y de los señores no se atreven los famosos fulleros a usar de sus tretas; y pues el vicio del juego se ha vuelto en ejercicio común, mejor es que se juegue en casas principales que no en la de algún oficial, donde cogen a un desdichado de media noche abajo y le desuellan vivo ${ }^{10}$.

¿Por qué en la segunda parte del Quijote Cervantes se permite opinar sobre qué garitos y casas de juego deberían abrir o cerrar, y qué significado tendría su digresión acerca del origen de los naipes? Quizás Cervantes sólo quería rebatir — y de paso ridiculizar - a Francisco de Luque Faxardo, un clérigo sevillano autor del compendio más minucioso acerca del mundo de la timba del Siglo de Oro: Fiel desengaño contra la ociosidad y los juegos. Utilíssimo a los confesores y penitentes, justicias y los demás, a cuyo cargo está limpiar de vagabundos, tahúres y fulleros la República Christiana $^{11}$.

Redactado con una finalidad admonitoria y moralizadora, el Fiel desengaño no fue la primera obra publicada en España contra los naipes y

${ }^{9}$ Ibídem, parte II, cap. XXIV, p. 672.

${ }^{10}$ Ibídem parte II, cap. XLXIX, p. 767.

${ }^{11}$ Francisco Luque Faxardo: Fiel desengaño contra la ociosidad y los juegos. Utilíssimo a los confesores y penitentes, justicias y los demás, a cuyo cargo está limpiar de vagabundos, tahúres y fulleros la República Christiana (impreso en Madrid en Casa de Miguel Serrano de Vargas, año de 1603). Cito la edición de Martín de Riquer para la Biblioteca Selecta de Clásicos Españoles de la Real Academia Española (Madrid, 1955), 2 vols. 
el juego ${ }^{12}$, aunque sí se le puede considerar como el tratado más ameno sobre las trampas y los peligros de las cartas, así como la principal fuente del léxico de la timba y la fullería, pues ni el Tesoro de Covarrubias ni el Diccionario de autoridades recogen todas las voces y expresiones acuñadas en "coimas", "garitos", "tablajes", "leoneras", "ginebras", "mandrachos", "palomares" y otros sinónimos de las casas de juego de la época ${ }^{13}$.

Así, cuando Cervantes se pronunciaba a favor de la tolerancia del juego en casas de grandes personajes y caballeros principales, en realidad estaba refutando las ideas de Luque Faxardo, inflexible acerca de la conducta ejemplar que debían de tener los grandes personajes y caballeros principales:

¿Hay torpeza igual como aquesta, que las manos de los que deben dar ejemplo y ocuparse en ofrecer sacrificios a nuestro gran Dios, aplacándole en sus cóleras y enfados con los pecadores, poniéndose como otro Aarón, con el incensario en las manos, entre la Majestad suya y el pueblo, verlos adorando unas pinturas y sabandijas del naipe, no dibujadas en la pared, si no en papeles y cartas del demonio, como ya queda advertido en su lugar? . . ¿ ¿Qué ha de hacer el otro mozo holgazán y vicioso si ve que el ejemplar se sienta con él igualmente al tablero, gastando en eso lo más del tiempo? Verdaderamente, el pueblo tiene puestos los ojos en ellos; y viéneles muy a cuento a los viciosos para dar rienda suelta a sus demasías decir: "Fulano juega"; y con tales circunstancias que, haciendo comparación, no hay de qué espantarse que jueguen ellos ${ }^{14}$.

Por otro lado, Martín de Riquer advirtió que Luque Faxardo glosaba a Virgilio Polidoro en los capítulos dedicados al origen de los naipes, aunque sin citarlo" ${ }^{15}$ y de ahí dedujo que "Cervantes, en la persona del primo, está satirizando la erudición anticuaria de Luque Faxardo en lo que se refiere al origen de los naipes. Y tal sospecha se robustece si tenemos en cuenta que unos capítulos antes, en la misma segunda parte del Quijote, aparece

${ }^{12}$ En el siglo XVI se publicaron dos libros sobre la materia: Pedro de Covarrubias, Remedio de jugadores (en Burgos, por arte e industria de Alonso de Melgar impresor, año de 1519); y fray Francisco de Alcocer, Tratado del juego (impreso en Salamanca en casa de Andrea de Portonaris, 1559).

${ }^{13}$ Luque Faxardo, Fiel desengaño..., op. cit., t. I, p. 107.

${ }^{14}$ Luque Faxardo, Fiel desengaño..., op. cit., t. II, p. 184.

${ }^{15}$ Luque Faxardo sólo cita a Virgilio Polidoro en el Libro II, cap. I (t. I, p. 188) y en el Libro III, cap. I (t. II, p. 89), pero no lo menciona en todo el Libro I, dedicado al origen de los naipes. La obra de Polidoro Virgilio se titulaba Libro que trata de la invención y principio de todas las cosas, traducido por Francisco Thamara (Anvers, Nucio, 1550 [en Medina del Campo se reeditó en 1551, 1586, 1597 y 1598]). 
un cierto paralelismo con un pasaje del Fiel desengaño contra la ociosidad y el juego" 16 . Sin embargo, una ironía del destino ha querido que el tratado de Luque Faxardo sea imprescindible para reconocer las "flores" o trampas enumeradas por Cervantes en Rinconete y Cortadillo y en la comedia $\mathrm{Pe}$ dro de Urdemalas. A saber, "andaboba"17, "floreo de Vilhán", "retén", "humillo", "sola", "cuatro", "ocho", "raspadillo", "verrugueta", "colmillo", "la boca del lobo", "tercio de chanza", "astillazo", "ballestilla", "respaldillo", "hollín”, "Maese Juan” y "espejuelo"18.

${ }^{16}$ Martín de Riquer, "Prólogo" a Fiel desengaño..., op. cit., t. I, p. 16.

17 Cervantes menciona esta "flor" al comienzo de Rinconete y Cortadillo: "aprendí de un cocinero de un cierto embajador ciertas tretas de quínolas y del parar, a quien también llaman el andaboba" (Obras Completas, op. cit., t. II, p. 81). Según el Diccionario de autoridades, op. cit., "AnDABOBA: Trampa o fullería que usan los fulleros al juego de quínolas y del parar. Lat. Fraudulenta chartarum techna” (t. I).

${ }_{18}$ No es posible - sin embargo - descifrar todas las "flores" o trampas. En Luque Faxardo aparecen las siguientes: Tercio DE CHANZA: "Otros llaman naipes del tercio, respecto que la fullería está en la tercera parte de la baraja, como traza encaminada en daño de terceros" (t. II, p. 25); Astillazo: "Cuando uno déstos quiere quitar las suertes, que derechamente vienen a su contrario, vuelve a recorrer las cartas, poniendo en medio otra; y a esto llaman dar astillazo" (ibídem, 26); BALlestilla: "Otra flor llaman la ballestilla: debe ser sin duda por las heridas de saeta con que quitan el dinero" (ibídem, loc. cit.); Verruguilla: "esta flor sin duda se compone de esas dos condiciones de animales, encaminándose a despojar la hacienda ajena sin nota ni ruido, bien que varían en el modo y nombre de sus fullerías; pero todo a fin de robar. A una llaman berruguilla, a otra hacer la teja" (ibídem, p. 35) y La BOCA DEL LOBO: "a lo cual dicen ellos, por vía de chanza, ser sus lamedores más activos que purga de otros, con unas largas metáforas que siguen al propósito, pasándose ordinariamente en risa, como negocio de donaire" (ibídem, p. 36). En un curioso estudio, el erudito Francisco Rodríguez Marín _ "Las flores de Rinconete", en Ensaladilla. Menudencias de Varia, Leve y entretenida erudición (Madrid, 1923), pp. 67-78 - identifica algunas "flores" más. A saber, RETÉN: "esta maniobra consistía, según el vocabulario germanesco de Juan Hidalgo (1609), en tener el naipe cuando el fullero juega, que se suele decir salvar, y ellos dicen salvatierra" (p. 74); HumiLlo: "Este, como el lápiz y el hollín, y a diferencia de la pez, consistía en señalar sutilmente por el dorso tales o cuales suertes de naipes, o todos ellos, distinguiéndolos según los sitios en que estaban marcados" (p. 74); SolA, CuAtro y OCHO: "Todo esto equivalía a apandillar o juntar la suerte o algún encuentro, llevándolo abajo o arriba; a reservarse uno o varios naipes mientras cortaban, poniéndolos luego, a dos por tres, donde era necesario para que salieran a la mesa o se quedaran de por vida en la baraja" (p. 75) y Raspadillo, Verrugueta y Colmillo: "Tres flores que consistían en señalar los naipes para distinguirlos al tacto, ya raspándolos sutilmente en determinados lugares, según las suertes, ya apretando sobre la haz de tales o cuales de ellos la cabeza de un alfiler, de modo que por el envés la señal semejaba una verruguilla, o bien pulimentándolos extremadamente acá o allá, operación que de ordinario se hacía con un colmillo de cerdo, de donde tomó el nombre esta flor” (p. 75). En cuanto al Floreo de Vilhán, Luque Faxardo dedica dos capítulos a este demonio presunto inventor de los naipes, precisando que los tahúres "en los sucesos de pérdida o ganancia se dan pésames y plácemes, diciendo ser aquel dinero bienes de Vilhán, a cuya disposición está quitarlos o hacer merced dellos a quien más le place, hoy a Juan, mañana a Pedro, acompañando sus patrañas con cuentos que no son para aquí; y en particular a los tahúres novatos o chapetones, rematando sus prolijos discursos (cuando más alcanzados de sufrimiento a causa de las pérdidas) con la vulgar proposición, que dice: paciencia y barajar" (Luque Faxardo, Fiel desengaño..., op. cit., t. I, p. 97. El subrayado es nuestro). 
No obstante, una cosa eran las "flores" y otra muy distinta los juegos donde tales trampas podían ponerse en práctica. Y aunque Cervantes no fuera un fullero, un tahúr o un tramposo, no hay que olvidar que sí fue un jugador.

\section{La polla y los juegos de manos}

La baraja fue una fuente inagotable de diversión y entretenimiento durante unos años en los que apenas existían otras opciones de ocio fuera del teatro y la lectura. Como cualquier otro hombre de su tiempo, Cervantes sucumbió al hechizo de los naipes y por eso los nombres de los juegos del Siglo de Oro aparecen diseminados por sus obras.

Así, en el principio de La ilustre fregona (1613) Cervantes da cuenta de todo lo aprendido por el pícaro Carriazo en la "Cátedra de Alfarache":

En tres años que tardó en volver a parecer y volver a su casa aprendió a jugar a la taba en Madrid, y al rentói en las ventillas de Toledo, y a la presa y pinta en las barbacanas de Sevilla ${ }^{19}$.

La taba —en realidad - no era un juego de $\operatorname{cartas}^{20}$, pero aunque Covarrubias definía "presa y pinta" como "término de jugadores de naipes" 21 , con el Diccionario de autoridades sí podemos saber en qué consistían los juegos de la pinta y el rentói:

PINTAS. Juego de náipes, especie del que se llama del Parar. Juégase volviendo á la cara toda la baraja junta, y la primera carta que se descubre es del contrario, y la segunda del que lleva el náipe, y estas dos se llaman Pintas. Vanse sacando cartas, hasta encontrar una semejante á alguna de las que salieron al principio, y gana aquel que encuentra con la suya, tantos puntos, quantas cartas puede contar desde ella hasta dar con azár, que son el tres, el quatro, el cinco y el seis, sino es quando son pintas, o quando hacen encaxe al tiempo de ir contando: como por exemplo, si la quarta carta es un quatro, no es azár sino encaxe. El que lleva el náipe ha de querer los envites que le hace el contrario ú dexar el náipe ${ }^{22}$.

\footnotetext{
${ }^{19}$ Miguel de Cervantes, La ilustre fregona, en Obras completas, op. cit., t. II, p. 178.

${ }^{20}$ Según el Diccionario de autoridades la "taba" era un huesecillo de animal. "Juego de taba: El que usa la gente vulgar, tirándola por alto al suelo, hasta que quede en pie por los lados estrechos. Por la parte cóncava, que forma una $\mathrm{S}$, al modo de aquella con que se notan los párraphos, y se llama carne, gana el que la tira; y por la otra, que se llama culo, pierde" (Diccionario de autoridades, op. cit., t. III).

${ }^{21}$ Covarrubias, Tesoro..., op. cit., p. 833.

22 Diccionario de autoridades, op. cit., t. III.
} 
RENTÓI. Juego de náipes, que se juega de compañeros, entre dos, quatro, seis, y à veces entre ocho personas. Se dán tres cartas à cada uno, y después se descubre la immediata, la qual queda por muestra, y según el palo sale, son los triunfos aquella mano. La malilla es el dos de todos palos, y esta es la que gana à todas las demás cartas; sólo quando es convenio de los que juegan, que ponen por superiór à el quatro, à el qual llaman el borrégo, y la malilla se queda en segundo lugár, después el rey, caballo, sota, ás, y assí ván siguiendo el siete y las demás hasta el tres, que es la mas inferiór. Se juegan bazas como al hombre, y se envida como al truque, haciéndose señas los compañeros. Lat. Ludus chartarum pictarum sic dictus. Esteb. cap.3. Y sacando la lengua, como jugadór de rentói, y seña de malilla, me tenia fatigadas las oréjas. Cerv. Nov. 8. pl. 234. Aprendió à jugar à la taba en Madrid, y al rentói en las ventillas de Toledo, y à pressa y pinta en pié, en las barbacánas de Sevilla ${ }^{23}$.

En el capítulo XXXI de la Segunda Parte del Quijote, Sancho piropeó así - en vano - a doña Rodríguez de Grijalva, con intención de colocar a su asno en las caballerizas del castillo: "no perderá vuesa merced la quínola de sus años por punto menos" 24 . Según la edición crítica preparada por el Instituto Cervantes con ocasión del IV centenario de la edición del Quijote, "En el juego de la primera, quínola era la combinación de cuatro cartas del mismo palo" 25 , pero la combinación de cuatro cartas del mismo palo se llamaba "flux", tanto en el juego de la quínola como de la primera:

QuíNOLA. Juego de náipes en el que el lance principál consiste en hacer quatro cartas, cada una de su palo, y si la hacen dos, gana la que incluye mas puntos. Lat. Ludus es varietate chartarum sic dictus. PIC. JUST. 256. Pensó que mi casamiento era de casta de quínola, que se hace sin descarte. ESTEB. cap. 1. Señalando las cartas por las puntas para quínolas y priméra ${ }^{26}$.

PRIMERA. Juego de náipes, que se juega dando quatro cartas á cada uno: el siete vale veinte y un puntos, el seis vale diez y ocho, el ás diez y seis, el dos doce, el tres trece, el quatro catorce, el cinco quince, y la figura diez. La mejor suerte, y con que se gana todo es el flux, que son quatro cartas de un palo;

\footnotetext{
${ }^{23}$ Ibídem, t. III.
}

${ }^{24}$ Cervantes, Don Quijote, Obras completas, op. cit., t. II, p. 698.

${ }^{25}$ Cervantes, Don Quijote de la Mancha, edición del Instituto Cervantes 16052005 y dirigida por Francisco Rico (Barcelona: Galaxia Gutenberg \& Círculo de Lectores, 2005), tomo I, p. 963, nota 18. Para no dejar dudas: "FLUX. Term. Del juego de las quínolas y otros. El concurso de todas las cartas de un mismo palo. Lat. Simultas chartarum pictarum" (Diccionario de autoridades, op. cit., t. II).

${ }^{26}$ Diccionario de autoridades, op. cit., t. III. 
después el cincuenta y cinco, que se compone precisamente de siete, seis y ás de un palo; después la quínola o primera, que son quatro cartas, una de cada palo. Si hai dos que tengan flux, gana el que le tiene mayor, y lo mismo sucede con la primera; pero si no hai cosa alguna desto, gana el que tiene más punto en dos ó tres cartas de un palo. Lat. Ludus chartarum sic $\operatorname{dictus}^{27}$.

También en la Segunda Parte del Quijote, Sancho reniega de la caza como pasatiempo y pregona en alta voz su preferencia por los juegos: "En lo que yo pienso entretenerme es en jugar al triunfo envidado las pascuas, y a los bolos los domingos y fiestas"28. ¿Qué era el triunfo envidado? Según el Diccionario de autoridades, triunfo "Llaman también à un juego de náipes lo mismo que el del burro" 29 y envidado vendría de envidar: "Término del juego. Provocar, incitar, excitar à otro para que admita la parada, no para darle el dinero; sino para ganársela y llevárselo, si puede"30. Por lo tanto, el juego del triunfo nos lleva a definir los juegos del parar y del burro.

PARAR. Juego de náipes, que se hace entre muchas personas, sacando el que le lleva una carta de la baraja, á la qual apuestan lo que quieren los demás (que si es encuentro como de Rey y Rey, gana el que lleva el náipe) y si sale primero la de este, gana la parada, y la pierde si sale el de los paradores. Lat. $A d$ unicum folium lusorium sponsio vel depositio ${ }^{31}$.

BURRO. Se llama también un juego de náipes en que se dán tres cartas à cada jugadór, y se descubre la que queda encima de las que sobran, para señalar el triumpho de que ha de jugarse cada mano. El priméro à quien dán los náipes puede passar, y después jugar si le pareciere: los demás que passan no pueden entrar. Los ases son las superiores, y las figúras y demás cartas como al juego del hombre: y en defecto del triumpho señalado por la carta descubierta es la mayor el as, síguele el Rey, y las demás por su orden. Gana el juego quien mas bazas hace, y si hacen igualmente parten entre los tres que hicieron cada uno una baza, y el que no hace, ò los que no hacen, todos ponen lo que tenía la polla, ò lo que pactan los jugadóres. Lat. Pagellarum pictarum quidam ludus ${ }^{32}$.

${ }^{27}$ Ibídem, t. III

${ }^{28}$ Cervantes, Don Quijote, Obras completas, op. cit., t. II, p. 715.

${ }^{29}$ Diccionario de autoridades, op. cit., t. III.

${ }^{30}$ Ibídem, t. II.

${ }^{31}$ Ibídem, t. III.

${ }^{32}$ Ibídem, t. I. 
De la cita anterior se colige que la polla del burro era algo que tenían que poner los jugadores y no precisamente un burro. ¿Tendría alguna relación con aquel "juego del hombre" citado en las definiciones del burro y del rentói? Cervantes vuelve a mencionar la polla en un fragmento de El licenciado Vidriera (1613), colmado de referencias naipescas:

Alababa mucho la paciencia de un tahúr, que estaba toda una noche jugando y perdiendo, y con ser de condición colérico y endemoniado, a trueco de que su contrario no se alzase no descosía la boca y sufría lo que un mártir de Barrabás. Alababa también las conciencias de algunos honrados gariteros que ni por imaginación consentían que en su casa se jugase otros juegos que polla y cientos; y con esto a fuego lento, sin temor y nota de malsines, sacaban al cabo del mes más barato que lo que consentían los jueces de estocada, del repárolo, siete y llevar, y pinta en la del punto ${ }^{33}$.

La pinta ya la tenemos en nuestro inventario, pero con la excepción del misterioso repárolo sí hemos podido identificar los demás juegos y sus derivaciones naipescas, pues el siete y llevar es sólo el extremo de un hilo que nos conduce hasta la madeja de la bacéta:

Siete y LLEVAR. En el juego de la banca se llama la tercera suerte, en que se va á ganar siete tantos. Lat. Tertia sors in ludo chartarum septem puncta exponens ${ }^{34}$.

BANCA: Es en el juego de la bacéta la cantidad ó porción de dinero que pone de contado el banquero, que es el que lleva siempre el náipe, o que abona de palabra. Lat. Pecunia usura$\mathrm{ria}^{35}$.

BACÉTA: Juego de náipes modernamente introducido en España, que se execúta poniendo uno (que siempre lleva el náipe) una cantidád de dinero de contado (que llaman banca) y los que juegan contra este ponen sobre un náipe (el que cada uno elige a su fantasía) la cantidád que le paréce, y el banquéro con una barája vá echando cartas en dos montónes ó partes: si cae á la izquierda la que está parada por los jugadores (que a este juego llaman Apuntadóres) pierde, y si cae á la derécha gana. Es voz Francésa, en cuyo Idioma se le dá este nombre á este juego ${ }^{36}$.

\footnotetext{
${ }^{33}$ Cervantes, El licenciado Vidriera, Obras completas, t. II, p. 141.

${ }^{34}$ Diccionario de autoridades, op. cit., t. I.

${ }^{35}$ Ibídem, t. I.

${ }^{36}$ Ibídem, t. I.
} 
En el caso de los cientos, Covarrubias se limita a definirlo como "juego ingenioso y muy usado en España" ${ }^{37}$ y por desgracia carece de una entrada propia en el Diccionario de autoridades, aunque existe una referencia indirecta en la definición de quinta ${ }^{38}$. Por lo tanto, el último juego de manos que nos queda por averiguar es la polla de Cervantes:

Polla: En el juego del hombre y otros, se llama assí aquella porción que se pone y apuesta entre los que juegan. Lat. Ludis sponsio. M. León, Opr. Poet. tom. I. pl. 454.

Pedro por triumphar de espada, á la polla en contingencia puso, cantóle otro gallo, sino la polla perdiera ${ }^{39}$.

Como se puede apreciar, la polla no era un juego propiamente, sino el nombre de una apuesta dentro de uno en particular: el Juego del Hombre. El universo de los naipes del Siglo de Oro fue muchísimo más rico ${ }^{40}$, pero el Juego del Hombre reinó soberano durante siglos y sus lances y suertes fraguaron un campo semántico único, donde las pollas se remetían, se sacaban, se corrían y hasta se metían dobladas.

${ }^{37}$ Covarrubias, Tesoro..., op. cit., p. 309.

38 "Quinta: Se llama en el Juego de los Cientos cinco cartas de un palo seguidas en orden. Si empiezan desde el As, se llama mayor; si del Rey, real, y assí las demás, tomando el nombre de la principal carta por donde empiezan. Lat. In ludo quinque chartae lusoria ordine subsecute" (Diccionario de autoridades, op. cit., t. III).

${ }^{39}$ Diccionario de autoridades, op. cit., t. III.

${ }^{40}$ En el Tesoro... de Covarrubias y en el Diccionario de autoridades se consignan los siguientes juegos:

"BÁCIGA: Espécie de juego que se juega con náipes entre dos, ò más persónas con tres cartas, y en él se llama báciga el que en los tres náipes hace el punto, que no passa de nueve, y si le hacen à un mismo tiempo gana el que la tiene menor, y si igual, el que es mano. Después se toman cartas hasta hacer treinta y una, que es el mayor punto, ò el más cercano à él, y el que hace treinta y una gana dos puntos, y si hace el punto más cercano gana uno, y por cada pareja que hai en las cartas gana otro punto. El que hace en las primeras tres cartas as, dos, y tres de un palo gana el juego doble, y si le hace con pericón ò pendanga, que son caballo de bastos y sota de oros, gana el juego sencillo. Si en las cartas que ha tomado para hacer treinta y una, ò el punto más próximo, tiene quatrinca, esto es quatro asses, doses, treces, etc. gana juego. Y si en este número de cartas que toma hasta hacer el punto de treinta y una hai nueve cartas, gana un juego; y si diez, dos; y assí de los demás. Ordinariamente se juega á doce puntos, y el que primero los hace gana el juego. Medio juego se llama la báciga, que dentro de los nueve puntos es de un palo en las tres cartas priméras, y también lo es quando las tres cartas son tres asses, doses, ù otro cualquier punto o figura" (Diccionario de autoridades, t. I).

"CACHO. Juego de náipes, usado de pocos años à esta parte, que se hace con media baraja, dando a cada uno una carta, que van subiendo desde el as, hasta el seis. Si alguno envida, y los otros ó alguno quieren, se dá segunda carta al que envida, y al que 


\title{
Cómo se hacía un hombre en el Siglo de Oro
}

\author{
El Juego del Hombre fue el más popular de la baraja española y \\ conoció hasta cinco variantes que participaban de un mismo vocabulario \\ que servía para definir suertes, lances y figuras. A través de las fuentes \\ consultadas sólo hemos podido identificar las siguientes modalidades:
}

acépta. Si vuelven a envidar es la posta; y si no, passan y se dan las terceras, en que se puede volver a envidar hasta el resto. El mayor punto gana, que puede subir á treinta y una, si juntan cinco y seis de un palo. Tres naipes de un palo hacen cacho: si es el quatro, el cinco y el seis, es cacho mayor; y si juntan tres seises, es cacho que gana a todos; y con este solo puede envidar" (Diccionario de autoridades, op. cit., t. I).

"CAPADILLO. El juego del chilindrín, sin ochos y nueves, que por haberle quitado aquellas cartas le pusieron este nombre" (Tesoro..., op. cit., p. 261).

"ChILINDRÓN. Juego de cartas, usado en España; apacible y de conversación, del verbo griego $\chi \nu \lambda \iota v \delta \omega$ vel $\chi \nu \lambda \iota v \delta \varepsilon \omega$, voluo, porque van en rueda pidiendo cartas desde el as hasta el Rey. El que se juega sin ochos y nueves llaman el capadillo" (Tesoro, p. 390). "CHILINDRÓN. Juego de náipes, que se juega entre dos ò quatro personas, repartiendo los náipes por iguales partes à cada uno, y el que es mano empieza à jugar, echando las cartas que se siguen unas à otras en el número y pinta: como as, dos, tres. Y si no tiene quatro passa al segundo, o al que le tuviere, y continúa este, echando quatro, cinco y seis, y assí hasta sota, caballo y Rey, que estos tres náipes se llaman Chilindrón. Y el que en esta forma se descarta primero, gana de los otros por cada carta que no se han descartado, la cantidad que se impuso al empezar el juego. Es una especie de pechigonga sin envites" (Diccionario de autoridades, op. cit., t. I).

"Flor: Juego de náipes, en que de una en una se reparten tres cartas à cada sugéto de los que juegan, y se hacen los envites y revites del mismo mode que al cacho. El que hace flór, que son tres cartas de un palo, tiene mejor partido: y caso que concurra otro, gana el que tiene más puntos, y siendo iguales es superiór el que es mano. El dos vale doce, el as once, las figúras y el cinco diez, el tres nueve, el quatro ocho, y el siete y seis como pintan. El postre tiene el privilegio de que le valga diez la primera carta que toma, descubriéndola para que la vean los demás, aunque la tal carta sea seis, ò siete. Quando no se hace flor gana el mayór punto de los que ocurren en una ù dos cartas. Lat. Ludus chartarum pictarum sic vulgò dictus. Salaz. Obr. Posth. pl. 257. Tus mexillas al juego / le desconocen, / que à la flor solo juegan, / pero no al hombre” (Diccionario de autoridades, op. cit., II).

"Malilla. Juego de náipes nuevamente introducido, que se dispóne entre quatro personas, cada dos de compañeros, repartiendo las cartas à doce à cada uno, y el que las dá descubre la última suya, la qual es el triumpho aquella mano. Los demás palos se juegan como en el Hombre, teniendo todos precisión de servir ganando siempre, si puede por el orden de las cartas, que es la malilla ò nueve, superior à todas, luego el As, Rey, caballo, sota, siete, seis, etc. y si está fallo poner triumpho. El fin del juego es hacer treinta y seis piedras, las quales se cuentan del valor de las bazas, que cada uno hace, en las quales vale el nueve ò malilla cinco, el as quatro, el Rey tres, el caballo dos, y la sota uno: las blancas no valen nada, ni se cuenta más que la baza, que siempre añade un punto à los demàs. Acabada la mano y cotejado el excesso de puntos, este es el que se debe tantear; sino es que se hagan todas las bazas, lo qual llaman capote, que gana el juego. Juégase también cada uno para sí de la misma suerte, la qual llaman Alborotada: y entre dos, repartiendo todas las cartas, que llaman Peirote. Lat. Ludus chartarum à charta sic dicta denominatus" (Diccionario de autoridades, op. cit., t. II).

"Pechigonga. Juego de náipes, que se juega entre quatro en la forma siguiente. Danse quatro cartas à cada uno, y con ellas se envida ò passa, según el punto que se 
JuEGO DEL HomBre. Género de juego de náipes entre varias personas, con elección de palo, que sea triumpho, y el que le elige se llama hombre. Hai varias especies de él, jugándose unas veces, y con más o menos cartas, con descarte o sin él, y se le dan varios nombres: como la Zanga, la Cascarela, el Cinquillo y otros. La más principal y antigua es la que llaman del Renegado: y se juega entre tres, dando a cada uno nueve cartas, y el que tiene juego entra eligiendo triumpho, y para sacar la polla necesita de hacer cinco bazas, si no es que de los contrarios haga el uno tres y el otro dos: que entonces se bastan quatro para ganar. Lat. Ludus chartarum pictarum, sic vulgo dictus ${ }^{41}$.

ZANGA. El juego del hombre que se juega entre quatro, parecido al que llaman de la cascarela; sólo que las ocho cartas que quedan, á las quales llaman zanga, las toma el postre, después de haber passado todos quatro. $\mathrm{Y}$ de no tomarlas este, puede

tiene para ello, ò de falso. Si hai priméra ò flux, no se puede envidar sino es que alguno de los otros le tenga, y gana el que tiene primera ò flux mayor. Danse después otras quatro cartas, y con ellas se hace lo mismo que con las priméras. Después se dá otra carta sola à cada uno, y con ella, el que tiene siete ò seis, que son las mejores, envida y reenvida con punto de falso: luego juntando las nueve cartas se vuelve à envidar en todas, de lleno ò de falso, siendo el mejor punto cincuenta y cinco. Pechigonga es quando alguno en las nueve cartas las tiene consecutivas, esto es, as, dos, tres, etc. hasta la última: y à este se le paga un tanto en que se ha convenido. Este juego vino de Indias, de donde traxo el nombre. Lat. Ludus chartarum ordine numerandarum" (Diccionario de autoridades, op. cit., t. III).

"QUinCE [CINCO] Jugaban dos al quince, y el uno fue tomando cartas hasta cinco sin pasar; y el contrario tenía catorce, y habiéndole envidado el resto, quísole diciendo: ¿Qué puntos pueden ser los de cinco cartas, siendo yo mano? Púsola luego el compañero en el resto, y dijo: ¿No sabéis cuántas son cinco?, y descubrió una, dos, tres, cuatro, cinco corridas, que todas hacen quince" (Tesoro, op. cit., p. 314).

"Rentilla. Juego de náipes, en que se reparte una carta à cada uno de los que juegan, y sobre el punto que pinta la carta, se ha de pedir hasta hacer treinta y uno, que es el fin del juego, y con lo que se gana el todo de la polla, y si llegasse à exceder del número treinta y uno, ha de poner el excesso de puntos, siendole arbitrario al que pide carta, quedarse en el punto que quisiere, sin llegar al treinta y uno, por si acase los demas llegan à passarse, poder ganar por mayor punto. Lat. Chartarum pictarum ludus sic dictus" (Diccionario de autoridades, op. cit., t. III).

"Veintiuna. “. . . si vuesa merced es versado en este juego, verá cuánta ventaja lleva el que sabe que tiene cierto un as a la primera carta, que le puede servir de un punto y de once: que con esta ventaja, siendo la veintiuna envidada, el dinero se queda en casa" (Cervantes, Rinconete y Cortadillo, Obras completas, op. cit., t. II, p. 81).

"TRuQue. Juego de náipes, entre dos, quatro, ù mas personas, en que se reparten à tres cartas à cada uno, las que se ván jugando una à una para hacer las bazas, que gana el que echa la carta mayor por su orden, que es el tres, el dos, ás, y después el Rey, caballo, etc. excepto los cincos, y quatros, que se separan. En este juego hai envites de tantos de tres en tres, diciendo truco, tres más, tres más nuevo, y juego fuera, que es doce piedras; número, que suele ser la talla del juego. Lat. Chartarum ludus, in que per repetitas, vel iteratas sponsiones collusor provocatur" (Diccionario de autoridades, op. cit., t. III).

${ }^{41}$ Diccionario de autoridades, op. cit., t. II. 
hacerlo uno de los otros tres, y este que las toma, queda precisado á elegir juego. Lat. Chartarum pictarum ludus, á modo ludendi sic dictus ${ }^{42}$.

CASCARELA. Cierta espécie de juego del hombre entre quatro, que se reduce á que uno de ellos tomando una carta, ò yendo sin ninguna, toma las que quedan, y después de vistas elige un palo para jugar la polla. Y si la saca, le pagan calidad como si fuera solo; pero si la pierde, la paga. Tiene el que va á cascarela, privilegio de quitar la entrada á los otros, aunque estén antes que él. Y también de meterse en baraja sin jugarla, pagando la calidad, pero hasta cierto número de pollas, conforme se pacta. Es voz moderna, y algunos dicen ya cáscara por cascarela ${ }^{43}$.

RENEGADO. Juego del hombre entre tres, en que se reparten nueve cartas á cada uno. Lat. Ludus chartarum pictarum sic dictus $^{44}$.

El Juego del Hombre era en realidad un complejo juego de estrategia, donde un máximo de cuatro jugadores libraban una suerte de guerra en la que los únicos objetivos posibles eran ganar o impedir la victoria de cualquiera de los rivales. Cada jugador recibía nueve cartas y la baraja se colocaba al centro de la mesa para robar cartas en cada turno. Las espadas y los bastos representaban las armas de combate, las copas los triunfos y los oros el botín de las batallas.

Por otro lado, su repertorio de estrategias era enorme, los lances o jugadas riquísimos y ganaba el jugador que tras reunir cinco bazas se sacaba la polla o suma total de las apuestas. En la Biblioteca Nacional de Madrid, en el tomo 47 de los "Papeles curiosos manuscritos" de la colección del Duque de Osuna, podemos encontrar una antigua versión de sus reglas: "Primera, segunda, tercer y quarta parte del Juego del Hombre, en que juegan a España como Polla, entre los cinco Monarchas de la Europa, que se comprehenden en este juego" 45 . ¿Cómo dudar de la decencia de la palabra polla en los siglos XVII y XVIII? Por eso una polla podía ser una expresión metafórica sobre la pérdida de las colonias ${ }^{46} \mathrm{o}$ simplemente el regalo generoso de una espléndida señora ${ }^{47}$.

${ }^{42}$ Ibídem, t. III.

${ }^{43}$ Ibídem, t. I.

44 Ibídem, t. III.

${ }^{45}$ Biblioteca Nacional de Madrid (BNM), Mss/10932: Papeles Curiosos Manuscritos, t. 47 , ff. $98 \mathrm{v}-125 \mathrm{r}$ (siglo XVIII).

${ }^{46}$ Anónimo, Juégase el reyno de Sicilia, como polla, al juego del hombre (Madrid: Domingo Leal impresor, 1718).

${ }^{47}$ Jacinto Valledor, Letra á la tonadilla intitulada, EL REGALO DE UNA POLLA, que ofrece á la Muy Ilustre Ciudad de Barcelona la señora Gabriela Santos, que celebra el innato regocijo de sus muy dignos ciudadanos, en 25 de diciembre del presente año de 1771 (Barcelona: Pablo Campins impresor, 1774). 
No obstante, a comienzos del siglo XIX el Juego del Hombre se convirtió en el Tresillo y sus lances fueron rebautizados, sus expresiones malsonantes refinadas y las pollas fueron del todo amputadas ${ }^{48}$, porque un juego de manos donde un hombre era "el que entra la polla" 49 y hacerse un hombre no era otra cosa que "entrar à la polla" 50 , se prestaba a peligrosos juegos de palabras donde la polla podía terminar en otras manos y en otros juegos. Véase al respecto el siguiente soneto atribuido al Conde de Villamediana, que en cada verso riza el doble sentido del vocabulario del Juego del Hombre:

A UNA SEÑORA QUE SE FACILITABA POR DINERO ${ }^{51}$

Éntrale el basto siempre a la doncella cuando de oros el hombre no ha fallado; espadas su manjar es descartado, porque lo quiere asi la madre della.

La malilla, aunque deje de tenella no perderá tanto, es lo que le ha entrado; y si quiere elegir, porque ha robado, él es la copa, y la malilla es ella.

${ }^{48}$ Las reglas más antiguas del tresillo fueron recogidas por P.A.D.: Juego del tresillo ó del hombre, dividido en nueve lecciones (Madrid: Imprenta de Juan Palacios, 1832). Otros manuales tresillistas del siglo XIX fueron los siguientes:

- Anónimo, Colección general de juegos. Ajedrez, damas, villar, asalto, chaquete, dominó, oca, rocambor, mediator, hombre, tresillo, zángano, báciga, revesino, malilla, cientos, solo, etc. (Barcelona: Piferrer, 1839).

- D.V.A., Manual del jugador de tresillo (Madrid: Imprenta de Alejandro Gómez Fuentenebro, 1845).

- Francisco Baltasar de Urúburu, Tratado fundamental del tresillo (Bilbao: Establecimiento tipográfico de la Revista Mercantil, 1883).

- Claudio Nicasio Miguel y Ruiz, Libro del tresillo (Barcelona: Casa Provincial de la Caridad, 1891).

- Pedro de Veciana, El tresillo: Explicación clara, detallada y comprensiva de todas las suertes y peripecias que ocurren en tan ameno y dificil juego (Barcelona: Taller de F. Sabater, 1900).

49 "HomBre: En el juego se dice el que entra la polla, para jugarse solo contra los otros. Lat. In ludo sic dicto cartharum pictarum prcecipuas partes agens" (Diccionario de autoridades, t. II).

50 "Hacerse hombre: En el juego del hombre es lo mismo que entrar á la polla. Lat. In ludo chartarum pictarum prcecipuas partes agere" (Diccionario de autoridades, t. II).

${ }^{51}$ Soneto encontrado por Jean-Pierre Etienvre en la Biblioteca Nacional de Madrid (Mss/5913) y publicado en "El juego como lenguaje en la poesía de la Edad de Oro", en Edad de Oro, IV (Madrid: Universidad Autónoma de Madrid, 1985), pp. 47-69. Etienvre califica este soneto como "verdadera joya de la erótica de la baraja", pero admite: “. . . he de confesar (idesgraciadamente!) que no me resulta del todo claro el sentido de algunos versos" (Etienvre, ibídem, p. 61). 
Quien entrare a jugar, quien hombre fuere,

si de oros a triunfar no se dispone,

nunca ganar aquesta polla espere.

Carta de más, dinero no se pone

en esta mano; antes quien la diere

su basto encima, a la malilla pone $e^{52}$

Si una polla en manos de un aristócrata como el Conde de Villamedia$\mathrm{na}^{53}$ podía degenerar así, ¿qué no habría hecho el vulgo canalla con las suyas? De aquellas pollas estas pajas.

\section{Del pagellas deponere al vocabularium veneris}

Jean-Pierre Etienvre ha demostrado que en la poesía del Siglo de Oro "se habla poquísimas veces, en realidad, de los naipes", pero se hablaba "muchísimas veces, en cambio, con los naipes" "54. Aquel lenguaje figurado explotaba el doble y triple sentido de palabras como "meter", "doblar" y "sacar", que dentro del Juego del Hombre estaban siempre en función de la polla:

Meterse. En el juego de la cascarela es ceder la polla, conviniéndose á reponerla antes de elegir palo ${ }^{55}$.

${ }^{52}$ Los palos o "manjares" de la baraja española son bastos, espadas, copas y oros. La "malilla" es un "Término del juego del hombre. La segunda carta del estuche, superior á todos menos á la espadilla, que del palo de oros y copas es el siete, y de bastos y espadas el dos" (Diccionario de autoridades, op. cit., t. II). Por otro lado, "entrar" en el Juego del Hombre "es pretender jugar la polla, teniendo juego suficiente y runfla bastante para disputarla" (op. cit., t. II) y "robar" era "descartar algunas de las cartas que se han dado, tomando otras tantas de las que han quedado por repartir" (op. cit., t. III). Finalmente, "poner" "se toma assímismo por apostar" y "en el juego vale lo mismo que parar" (op. cit., t. III). La correcta comprensión del soneto supone atribuirle connotaciones eróticas a las expresiones "basto", "entrar" y "poner", así como jugar con el doble sentido de "malilla". Cuando "de oros el hombre no ha fallado" quiere decir que el hombre es rico; pero el verso "Éntrale el basto siempre a la doncella" no se refiere a la polla, porque la polla del soneto es la doncella. A saber, "Polla: Por translación se llama la muchacha ó moza de poca edad y buen parecer" (Diccionario de autoridades, op. cit., t. III). Sin embargo, en el verso "su basto encima, a la malilla pone", sí es lo que el lector está pensando.

${ }^{53}$ Don Juan de Tassis y Peralta (Lisboa, 1582; Madrid, 1622), Conde de Villamediana, Correo Mayor del Reino, poeta, criptomante y tahúr, fue acuchillado en Madrid por un desconocido que nunca fue hallado. Pudo ser asesinado por orden del Rey, ya que coqueteaba con la Reina. Quizás fue emboscado por sus cómplices del pecado nefando, descubiertos más tarde por el Santo Oficio. Tal vez un marido cornudo y airado fue quien acabó con su vida. Aunque - en realidad - acaso fue despachado por cualquiera de la muchedumbre de escocidos que Villamediana denigró en sonetos y sainetes.

${ }^{54}$ Etienvre, "El juego como lenguaje en la poesía de la Edad de Oro", op. cit., p. 49.

${ }^{55}$ Diccionario de autoridades, op. cit., t. II. 
Doblar la Parada. Phrase de los que juegan dados u otros juegos de envite, que vale poner cantidad doble de la que estaba puesta antes ${ }^{56}$.

SACAR CARTAS. Juego en los náipes. Lo mismo que sacar pajas $^{57}$.

Por lo tanto, si un jugador sacaba una carta de triunfo, podía meter la polla doblada y entonces exclamaba “¡Polla corrida, triunfo en mesa! ${ }^{58}$, porque en el Juego del Hombre no había nada mejor que sacar "una polla como una olla"59. De ahí los versos de Calderón que sirven de pórtico a nuestras pesquisas:

César el juego aprendió

y un día que le jugó,

teniendo basto, malilla,

punto cierto y espadilla,

la tal polla remetió.

La polla era tan omnipresente en el Juego del Hombre, que una expresión tan inofensiva como "El que falla y arrastra, se mete en la banasta" tenía una polla adentro, pues fallar "En el juego del hombre es tomar con triumpho el Rey ó carta de otro palo que uno salió jugando"60; arrastrar "En el juego del hombre es salir triumphando de las cartas superiores del palo que se ha elegido por el hombre, à que deben precisamente servir los demás que juegan con él, echando carta del mismo palo elegido"61, y meterse en la banasta era "Phrase familiar del juego del hombre con que se dá à entender que aquel que ha entrado á la polla, y no ha robado lo bastante para podérsela llevar probablemente, la dá por repuesta, metiéndose en baraja. Lat. Lusorias pagellas deponere, \& in reliquarum fasciculum immittere" . Y Y si lusorias pagellas era una baraja, parece razonable que una carta fuera una paja.

El Tresillo desterró la voz polla de su vocabulario, pero ella sigue remetida en frases propias del juego como "Antes puesta que codillo";

${ }^{56}$ Ibídem, t. II.

${ }^{57}$ Ibídem, t. III.

${ }^{58}$ En el tresillo la expresión se ha convertido en “ ¡Baza corrida, triunfo en mesa!".

${ }^{59}$ En el habla de los siglos XVI y XVII la "olla" - la comida, los manjares, la buena mesa - era sinónimo de plenitud y felicidad. Ya lo decía el refranero: "Después de Dios la olla, y lo demás es bambolla". Pero, ¿y después de la olla?

${ }^{60}$ Diccionario de autoridades, op. cit., t. II.

${ }^{61}$ Ibídem, t. I.

${ }^{62}$ Ibídem, t. I. 
"Solo sin fallo, capallo" o "Antes codillo que sacada", porque codillo "En el juego del hombre se llama assí el perder la polla"63, por no hablar de lo que se saca, se capa o se pone ${ }^{64}$. Sin embargo, en el Tresillo la suma de todas las apuestas no es la polla sino el "pocillo", cariñoso diminutivo que sin duda proviene de pozo, que "En el juego de la cascarela es cierto número de pollas, que se vá separando, para que no exceda de ello lo que se juega en una mano, y se van jugando uno á uno, hasta apurarlos. El número es arbitrario, porque unos hacen los pozos de ocho pollas, otros de diez y seis ú como se convienen al ponerse á jugar"65.

Hace más de doscientos años que dejó de jugarse en España el Juego del Hombre, pero expresiones como "Ir a por todas", "Echar el resto", "Jugar todas las bazas" o "Aceptar el envite", continúan — como la polla - dentro del caletre de los españoles del siglo XXI. Por eso suscribimos los razonamientos de Jean-Pierre Etienvre: "Los juegos de naipes que sirven de fundamento a ese lenguaje figurado ya no forman parte de nuestra experiencia; pero dicho lenguaje aflora por doquier en unos textos que seguimos leyendo, y lo poco que hoy día sabemos de estos juegos procede esencialmente del uso metafórico de lo que fue un lenguaje práctico. Un lenguaje común, por cierto, que ha venido a ser un lenguaje perdido"66.

\section{La puntita}

Los hispanohablantes de América Latina hemos conservado la original acepción castiza de la palabra polla, como apuesta, sorteo, lotería o quiniela; mientras que en España ya nadie asocia la polla a las gallinas tiernas, los juegos de naipes o las doncellas en edad de merecer; porque una polla en España sólo es - por culpa del Juego del Hombre- lo que se mete, se corre y se saca en el sentido más genital de la expresión ${ }^{67}$.

\footnotetext{
${ }^{63}$ Ibídem, t. I.

${ }^{64}$ El solo "En el juego del hombre se llama la suerte, sin ayuda de robo, ni compañero. Lat. Chartarum sors, sic vulgo dicta" (ibídem, t. III).

${ }^{65}$ Ibídem, t. III.

${ }^{66}$ Etienvre, "El juego como lenguaje en la poesía de la Edad de Oro", op. cit., p. 67.

${ }^{67}$ Con todo, no deja de llamar la atención que Camilo José Cela — tan minucioso como sicalíptico - no hubiera incluido una entrada para "polla" en su Diccionario secreto (Madrid: Editorial Alfaguara, 2 vols., 1968), a pesar de que Luis Besses sí la había recogido en 1905 en su Diccionario de argot español ó lenguaje jergal gitano, delincuente profesional y popular (Barcelona: Herederos de Manuel Soler), definiéndola como sustantivo plural - "Órganos genitales del hombre"- en la parte correspondiente al lenguaje usual proveniente del jergal (cito la edición facsímil del Servicio de Publicaciones de la Universidad de Cádiz, 1989, p. 133).
} 
Así, pensamos que hemos proporcionado indicios más que suficientes para suponer que el uso contemporáneo de la palabra polla proviene del Juego del Hombre y otros juegos de naipes de los siglos XVI y XVII, por lo que descartamos la teoría de la etimología latina —polla, ex pollutio venit - y sobre todo la hipótesis de la procedencia anglosajona, según la cual "polla" sería la traducción casi literal de cock [gallo], vulgarismo inglés de idénticas connotaciones venéreas y gallináceas. Pero no. La polla era una apuesta del siglo XVI, y Cervantes ya la metía doblada y la sacaba corrida en el Quijote y sus Novelas ejemplares.

La mano hay que darla por perdida, don Miguel, pero después de cuatrocientos años hemos salvado la polla.

San José de la Rinconada, verano de 2005. 